\title{
Marie-Madeleine Fragonard, La pensée religieuse d'Agrippa d'Aubigné et son expression
}

\section{Michele Mastroianni}

\section{(2) OpenEdition}

12 Journals

\section{Edizione digitale}

URL: http://journals.openedition.org/studifrancesi/34577

DOI: 10.4000/studifrancesi.34577

ISSN: 2421-5856

\section{Editore}

Rosenberg \& Sellier

\section{Edizione cartacea}

Data di pubblicazione: 1 novembre 2005

Paginazione: 406-407

ISSN: 0039-2944

\section{Notizia bibliografica digitale}

Michele Mastroianni, «Marie-Madeleine Fragonard, La pensée religieuse d'Agrippa d'Aubigné et son expression», Studi Francesi [Online], 146 (XLIX | II) | 2005, online dal 30 novembre 2015, consultato il 18 avril 2021. URL: http://journals.openedition.org/studifrancesi/34577 ; DOI: https://doi.org/10.4000/ studifrancesi.34577

Questo documento è stato generato automaticamente il 18 avril 2021.

\section{(c)}

Studi Francesi è distribuita con Licenza Creative Commons Attribuzione - Non commerciale - Non opere derivate 4.0 Internazionale. 


\title{
Marie-Madeleine Fragonard, $L a$ pensée religieuse d'Agrippa d'Aubigné et son expression
}

\author{
Michele Mastroianni
}

\section{NOTIZIA}

MARIE-MADELEINE FRAGONARD, La pensée religieuse d'Agrippa d'Aubigné et son expression, Paris, Champion («Bibliothèque Littéraire de la Renaissance», LIII), 2004, pp. 876.

1 Impresa altamente meritoria, da parte delle edizioni Champion, quella di ristampare il lavoro di M.-M. Fragonard comparso nel 1981 nell'Atelier des thèses de Lille (ristampa: Paris, Didier Érudition, 1986). Si tratta infatti - basterebbe il nome dell'autrice a garantirlo - di un monumento della critica su d'Aubigné, particolarmente d'attualità nel fervore di studi su questo autore, testimoniato dal succedersi di edizioni critiche (ad esempio, le Cuvres complètes in corso di pubblicazione presso Champion) e dalla fortuna di una rivista («Albineana») a lui consacrata. Analisi approfondita della scrittura religiosa di Agrippa d'Aubigné e ricostruzione del suo pensiero religioso, la thèse spazia in un campo ben più vasto e metodologico, affrontando «l'enigma che pone qualsiasi prodotto di letteratura religiosa che per sua natura stessa si pone all'intersecarsi di due istituzioni e deve assimilare allo stesso tempo le norme di un'estetica del linguaggio e di una ortodossia, ma complicate dal fatto che, alla fine del XVI secolo, l'estetica e l'ortodossia sono male delimitate e l'autore è particolarmente cosciente della precarietà dell'una e dell'altra. [...] Il doppio postulato di una scrittura aperta al mondo e, in quanto tale, legata alla storia presente, al pubblico, alla passione, e di una scrittura che sia aperta all'Eternità e all'Ordine divino, ne rappresenta tutta la difficoltà. Il lettore si trova confrontato con degli universi che comprende soltanto attraverso metodi di analisi differenti (storia, retorica, poetica, teologia), e l'opera stessa diventa la prova della loro compatibilità al servizio di una ricerca di cui egli è invitato a ricostituire la logica» (p. 9). Il grande interesse della thèse di M.-M. Fragonard si fonda 
su presupposti che permettono di risolvere problemi di metodologia e di lettura propri della letteratura religiosa in genere. La premessa programmatica all'indagine concernente l'opera di d'Aubigné ci appare valida anche per l'approccio ad altri autori 'religiosi', se solo leggiamo quanto sottolinea in apertura Fragonard: «l'universo descritto da Agrippa d'Aubigné è organizzato secondo un pensiero profondamente mitico. Usando consapevolmente questo termine pittosto che 'religioso', vogliamo sottolineare il carattere drammaturgico (o narrativo) delle sue categorie di pensiero: per d'Aubigné, il mito coinvolge veramente lo sviluppo e la struttura di una Storia e, comunque, un dinamismo; il mondo non si accontenta di essere presente, le realtà sono considerate come tensione e vita, nulla è statico, bensì è teso verso la sua fine, verso la sua reintegrazione in seno al creatore. L'elemento centrale di questo mondo mitico è la nozione di immagine, che assicura, a partire da Platone, poi attraverso i Padri della Chiesa greca, una funzione essenziale nella riflessione. Dal momento che immagine esprime allo stesso tempo differenza degli esseri e somiglianza, dunque identità, degli esseri, questa nozione permette di esprimere la tensione vitale del mondo, che si differenzia da Dio, ma che si dirige verso Dio; essa esprime la separazione tra Dio e natura, senza peraltro supporre una loro alterità radicale. D'Aubigné adotta dunque una nozione tradizionale, che gli permette di abbozzare una Storia del Mondo» (p. 49). In effetti, tutta la concezione dell'autore concernente i diversi approcci di lettura possibili può valere per ogni analisi di letteratura religiosa: così è per l'approccio che si basa sul rapporto fra linguaggio mistico ed esperienza esistenziale; per quello che tenta di rapportare i testi ai contenuti dottrinali in genere e teologici in particolare; per quello che cerca dei nessi (e questo vale in particolare per la letteratura religiosa tra Cinque e Seicento) tra il testo in questione e la rispettiva area confessionale di spiritualità; per quello infine che cerca di descrivere la letteratura religiosa come un tipo di linguaggio governato da norme rigorose (retoriche) in rapporto a un testo modello quale la Bibbia. L'autrice parte poi dalla considerazione che «nell'analisi fatta dagli autori del XVI secolo, il linguaggio non è uno strumento neutro, ma è già l'oggetto di una rappresentazione che lo include nel divenire del mondo; attraverso le vicissitudini della storia, esso è ancora legato al Logos creatore. [...] L'espressione umana è concepita come una mimesis dell'espressione divina, che ha creato il mondo e l'uomo. Questo assioma può essere sviluppato sotto forma di un certo numero di luoghi comuni [...]; luoghi comuni che si cristallizzano in modo particolare su dei passaggi biblici (la Creazione, la distruzione della torre di Babele, la Pentecoste) e intorno alla Bibbia stessa» (p. 15). Da questa considerazione l'autore muove a creare una rete di mythes du langage su cui commisura i testi di Agrippa d'Aubigné. Una rete che corrisponde a un ordine dogmatico, le cui tappe sono le seguenti: Dio (pp. 57-136), l'uomo (pp. 137-200), l'universo a immagine di Dio (pp. 201-252), il male (pp. 259-305), il mondo alla rovescia (pp. 307-371), la demonologia (pp. 373-419), la conversione e la salvezza (pp. 427-489), l'ecclesiologia (pp. 491-552), i sacramenti (pp. 553-588), le relazioni del tempo e dell'eternità (pp. 595-662), le strutture luminose dell'universo (pp. 663-735). La ricca bibliografia è stata aggiornata, fornendo un ulteriore strumento ai ricercatori del campo. 